\title{
Two HEmostasis Methods After Transradlal Catheterization: THEMATIC - protocol for a randomized clinical trial
}

\author{
Dois métodos de hemostasia após cateterismo transradial: THEMATIC - protocolo \\ de ensaio clínico randomizado \\ Dos métodos de hemostasia luego de un cateterismo transradial: THEMATIC - protocolo \\ de ensayo clínico aleatorizado
}

How to cite this article: Santos SM, Rabelo-Silva ER, Aliti GB, Romero PS, Corrêa CL, Valle FH, et al. Two HEmostasis Methods After Transradlal Catheterization: THEMATIC - protocol for a randomized clinical trial. Rev Gaúcha Enferm. 2018:39:e2017-0257. doi: https:// doi.org/10.1590/1983-1447.2018.20170257 a Hospital de Clínicas de Porto Alegre (HCPA). Porto Alegre, Rio Grande do Sul, Brasil.

- Universidade Federal do Rio Grande do Sul (UFRGS), Escola de Enfermagem, Programa de Pós-graduação em Enfermagem. Porto Alegre, Rio Grande do Sul, Brasil.

Universidade Federal do Rio Grande do Sul (UFRGS), Faculdade de Medicina. Porto Alegre, Rio Grande do Sul, Brasil.
Simone Marques dos Santos ${ }^{a}$ Eneida Rejane Rabelo-Silva ${ }^{a, b}$ Graziella Badin Aliti ${ }^{b}$ Paola Severo Romero ${ }^{a}$ Camille Lacerda Corrêa ${ }^{a}$ Felipe Homem Valle ${ }^{a}$ Sandro Cadaval Gonçalves ${ }^{a}$ Marco Vugman Wainstein ${ }^{\mathrm{a}, \mathrm{c}}$ Rodrigo Vugman Wainstein ${ }^{\mathrm{a}}$

ABSTRACT

Objective: Randomized clinical trial protocol to evaluate the incidence of radial artery occlusion with two different arterial compression devices after transradial procedures.

Methods: Barbeau's test will be performed in adults scheduled to undergo transradial interventional procedures. Those with A, B, or C plethysmographic patterns will be selected. At the end of the procedure, patients will be randomly assigned (1:1) to receive patent haemostasis with TR Band ${ }^{\text {TM }}$ device or conventional haemostasis with an elastic adhesive bandage. The primary outcome is the incidence of radial artery occlusion. Secondary outcomes are Barbeau's test curve change, additional time to achieve haemostasis, incidence of bleeding at the puncture site, pain severity, development of arteriovenous fistula, radial pseudo aneurysm, any access-site complication requiring vascular surgery intervention and costs between the two devices.

Discussion: The results of this trial should provide valuable additional information on the best approach for haemostasis after transradial percutaneous cardiovascular interventions.

Keywords: Randomized controlled trial. Cardiac catheterization/adverse effects. Radial artery. Hemostatic techniques.

\section{RESUMO}

Objetivo: Protocolo de ensaio clínico randomizado para avaliar a incidência de oclusão da artéria radial com dois dispositivos diferentes de compressão arterial após procedimentos transradiais.

Métodos: 0 teste de Barbeau será realizado em adultos que serão submetidos a procedimentos de intervenção transradial previamente agendados. Aqueles com padrões pletismográficos A, B ou C serão selecionados. No final do procedimento, os pacientes serão distribuídos aleatoriamente (1:1) para receber hemostasia patente com dispositivo TR Band ${ }^{\text {TM }}$ ou hemostasia convencional com bandagem elástica adesiva. 0 desfecho primário é a incidência da oclusão da artéria radial. Os desfechos secundários são alteração da curva do teste de Barbeau, tempo adicional para atingir a hemostasia, incidência de sangramento no local da punção, intensidade da dor, desenvolvimento de fístula arteriovenosa, pseudoaneurisma, qualquer complicação no local de acesso que necessite intervenção cirúrgica vascular e custos entre os dois dispositivos.

Discussão: Os resultados deste estudo devem fornecer informações adicionais valiosas sobre a melhor abordagem para a hemostasia após intervenções cardiovasculares percutâneas transradiais.

Palavras-chave: Ensaio clínico controlado aleatório. Cateterismo cardíaco/efeitos adversos. Artéria radial. Técnicas hemostáticas.

\section{RESUMEN}

Objetivo: Protocolo de ensayo clínico randomizado para evaluar la incidencia de oclusión de la arteria radial con dos dispositivos de compresión arterial después de pasar por procedimientos transradiales.

Método: Se realizará el test de Barbeau en adultos que están esperando una intervención transradial. Se seleccionarán aquellos con padrones pletismográficos A, B o C. Al final del procedimiento, se dividirán a los pacientes de forma aleatoria (1:1) para recibir la hemostasia patente con dispositivo TR Band ${ }^{\text {TMM }}$ hemostasia convencional con vendaje elástico adhesivo. El resultado primario es la incidencia de oclusión de la arteria radial. Los resultados secundarios son la alteración de la curva del test de Barbeau, tiempo adicional para alcanzar la hemostasia, incidencia de sangrado en el local de la punción, intensidad del dolor, desarrollo de una fístula arteriovenosa, pseudoaneurisma, cualquier complicación en el lugar de acceso que necesite intervención quirúrgica vascular y costos entre ambos dispositivos. Discusión: Los resultados de este estudio deben proporcionar informaciones adicionales valiosas sobre un mejor enfoque para la hemostasia luego de intervenciones cardiovasculares percutáneas transradiales.

Palabras clave: Ensayo clínico controlado aleatorio. Cateterismo cardíaco/efectos adversos. Arteria radial. Técnicas hemostáticas. 


\section{口INTRODUCTION}

The radial artery approach for cardiac catheterization, coronary angiography, and percutaneous coronary intervention $(\mathrm{PCl})$ is associated with lower mortality and major adverse cardiac events (MACE) $)^{(1)}$. It also reduces the risk of local vascular complications, provides greater patient comfort, and enables earlier mobilization and ambulation. Moreover, it also shortens hospital length of stay and, consequently, decreases costs. Therefore, the radial artery has become the preferred route for diagnostic and therapeutic interventional cardiology procedures in current guidelines ${ }^{(2-3)}$. When compared to the femoral artery approach, the radial route has a longer learning curve, and interventional cardiologists with greater experience in this approach achieve better outcomes than do interventionists with less experience ${ }^{(3)}$.

Data from a multicentre trial that enrolled 7,021 patients from 32 countries and assessed the rate of complications with radial vs. femoral artery approaches during diagnostic coronary angiography and $\mathrm{PCl}$ show a lower rate of complications with transradial access. Regarding local vascular complications 30 days after procedure, hematoma was seen in 42 patients in the radial artery group and in 106 patients in the femoral artery group $(p<0.0001)$; pseudo aneurysms requiring surgical intervention were also significantly more common $(p=0.006)$ in the femoral artery group ( 27 vs. 7 cases in the femoral and radial groups respectively). These results demonstrate that both arterial access routes are safe, but the radial approach is associated with a lower rate of vascular complications, and its usage as the arterial route of choice should be encouraged ${ }^{(4)}$.

Although the risk of local vascular complications appears to be inherently lower with the radial artery approach than with the femoral approach, this risk reduction might be improved further or even maximized through the development and adoption of systematic care protocols. Radial artery occlusion (RAO) is a particularly prevalent complication ${ }^{(5)}$, possibly occurring after up to $10 \%$ of transradial procedures ${ }^{(6)}$.

Strategies to prevent local vascular complications should begin during preparation for the procedure. First, the patency of the palmar arch must be tested before radial artery puncture. The most common test for this purpose is Allen's test, in which the collateral circulation of the hand is tested through evaluation of the radial and ulnar arteries ${ }^{(7)}$. Another way to check palmar arch patency is the oximeter test, also known as Barbeau's test. This test is simple, objective, user-friendly, and more sensitive than Allen's test ${ }^{(8)}$.

Several interventions have demonstrated efficiency for the prevention of RAO, including use of $\leq 5$ French cath- eters and sheaths, systemic anticoagulation, and patent haemostasis. Patent haemostasis is a strategy that consists of providing distal blood flow to the hand during arterial compression. This approach proved useful in a previous single-centre randomized clinical trial (RCT) that compared two different strategies: haemostasis guided by mean arterial blood pressure (MAP) vs. routine insufflation of the cuff with $15 \mathrm{ml}$ of air. This study was interrupted early due to a $10.9 \%$ decrease in the incidence of radial artery thrombosis with the MAP-guided haemostasis strategy $(p<0.0001)$. Moreover, there were no differences in other outcomes between the two evaluated strategies ${ }^{(9)}$. The different types of compression bands available may interfere with the incidence of RAO, as demonstrated in a non-randomized study ${ }^{(10)}$.

In this scenario, there are other important issues that need to be addressed in relation to the quality and safety of care provided after transradial interventions, such as the duration of arterial compression and the grade of discomfort that these devices might induce. In an RCT that compared two different devices for radial artery compression, the TR Band ${ }^{T M}$ device was superior to the Radistop ${ }^{T M}$ device in terms of comfort: $77 \%$ of patients in the TR Band ${ }^{\text {TM }}$ group felt comfortable during compression vs. $61 \%$ of those allocated to Radistop ${ }^{\text {TM }}$. On the other hand, individuals allocated to the Radistop ${ }^{\mathrm{TM}}$ group required a shorter duration of arterial compression (289 min with Radistop ${ }^{\mathrm{TM}}$ and 319 min with TR Band ${ }^{\mathrm{TM}} \mathrm{M}$. The incidence of RAO was similar in the two groups $\left(9.6 \% \text { with TR Band }{ }^{\mathrm{TM}} \text { vs. } 8.9 \% \text { with Radistop }{ }^{\mathrm{TM}}, \mathrm{p}=0.9\right)^{(11)}$.

The radial approach has been adopted worldwide as the preferred route for most interventional cardiology procedures. However, there is insufficient evidence for the selection of radial artery compression devices. In this setting, the randomized clinical trial protocol reported herein aims to evaluate the incidence of RAO with two different arterial compression devices after transradial procedures.

\section{$\square$ METHODS}

\section{Study design}

Randomized Clinical Trial (RCT), parallel, single-centre, open-label, randomized clinical trial will enrol individuals scheduled to undergo diagnostic or therapeutic interventional cardiology procedures through the radial artery approach at Hospital de Clínicas de Porto Alegre (HCPA), a public hospital affiliated with the Universidade Federal do Rio Grande do Sul and located in southern Brazil (Trial registration number: ClinicalTrials.gov - identifier NCT02873871). 


\section{Eligibility and exclusion criteria}

Adults scheduled to undergo diagnostic and therapeutic interventional procedures through the right radial artery approach will be selected. Barbeau's test will be performed in all subjects to evaluate the patency of the palmar arch. In this test, the radial artery is compressed while the patient wears a fingertip pulse oximeter. The appearance of the plethysmographic waveform on the oximeter screen during radial artery compression is classified into one of four patterns: $A$, no curve damping after radial artery compression; $\mathrm{B}$, curve damping; $\mathrm{C}$, momentary loss of flow followed by recovery of the pulse tracing within 2 minutes; and D, loss of tracing without reestablishment of the curve ${ }^{(8)}$. The exclusion criteria will be: a D pattern on Barbeau's test, left radial approach to the heart, and impaired understanding of the study during administration of the informed consent form.

\section{Ethical issues}

The study protocol was approved by the local institutional ethics committee (protocol number CAEE 49237115.5.0000.5327). The study will be conducted in accordance with the principles of the Declaration of Hel- sinki and Brazilian regulatory guidelines for research with human subjects. Moreover, all participants will be asked to provide written informed consent.

\section{Sample size estimation}

The sample size of this protocol was based on a previous study that demonstrated a $12 \%$ incidence of radial artery occlusion after coronary angiography performed through the radial approach when a conventional haemostasis device was applied ${ }^{(12)}$. To detect a 7\% difference between conventional haemostasis approaches and patent haemostasis, with $80 \%$ power, a $20 \%$ missing data rate, and a significance level set at 0.05 , the sample size was estimated as 600 individuals.

\section{Study protocol and interventions}

Barbeau's test will be performed in all participants during preparation for cardiac catheterization and/or percutaneous coronary angioplasty. At the end of the procedure, patients will be randomly assigned (1:1) to receive haemostasis with a TR Band ${ }^{\text {TM }}$ device (intervention group, IG) or with an elastic adhesive bandage (control group, CG). Interventions of the study are described in Figure 1.

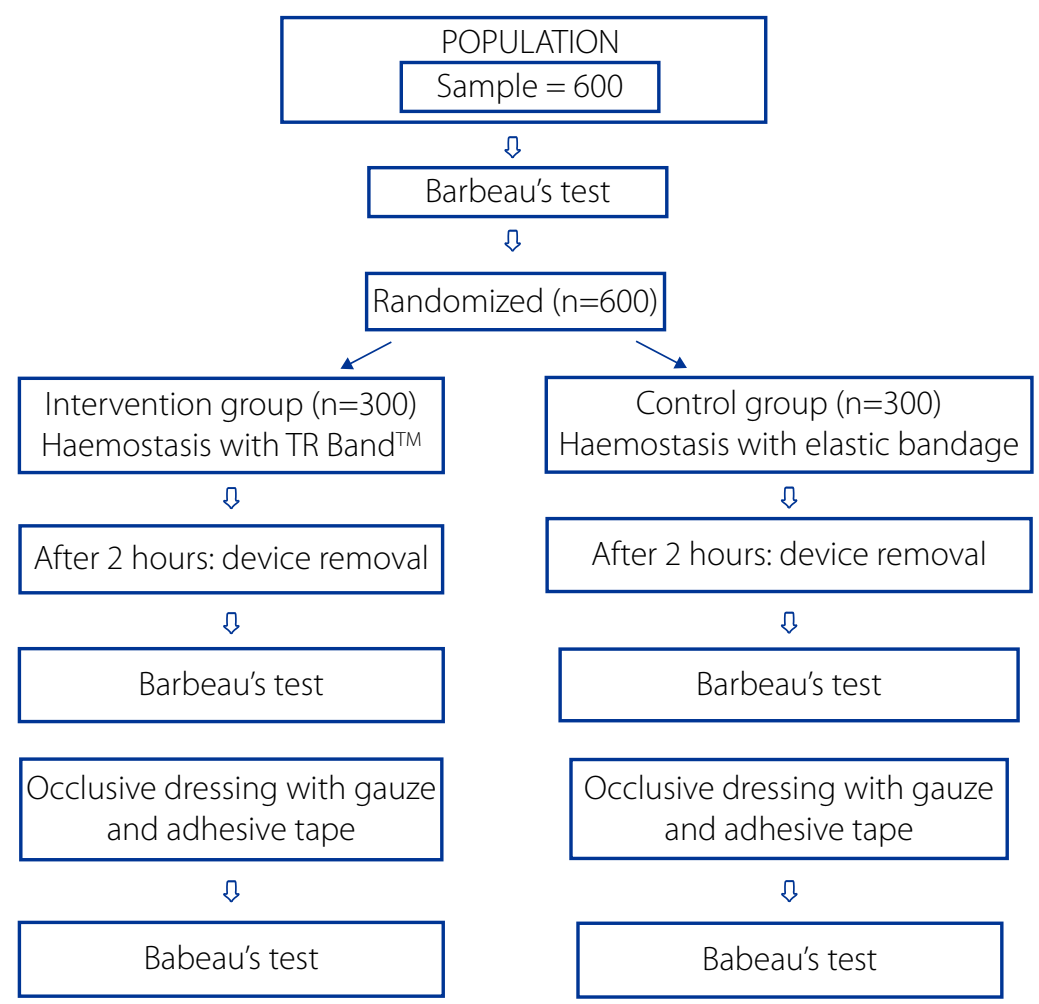

Figure 1- Flowchart of study participation and interventions Source: Authors. 
Intervention group: haemostasis with TR Band ${ }^{\mathrm{TM}}$ device. Placement of the TR Band ${ }^{\text {TM }}$ patent haemostasis device will be performed by a nurse with the assistance of the physician who performed the procedure. The device will be inflated with $13 \mathrm{ml}$ of air on average, or until there is no bleeding. After 2 hours of compression, the device will be deflated gradually ( $2 \mathrm{ml}$ every 10 minutes) and removed at the end of 2 hours and 30 minutes if no active bleeding is detected. After complete removal of the device, the puncture site will be covered with a conventional dressing (bandage, gauze, and tape), and Barbeau's test will be performed.

Control group: haemostasis with elastic adhesive bandage. Dressing with elastic adhesive bandage will be performed by a nurse with the assistance of the physician who performed the procedure. This technique consists of the application of a compact gauze swab above the radial artery puncture site, followed by a band of adhesive tape and two bands of elastic adhesive bandage placed in an " $X$ " shape over the adhesive tape, without encircling the arm. After 2 hours of compression, the device will be removed if no active bleeding is detected. After complete removal of the device, the puncture site will be covered with a conventional dressing (bandage, gauze, and tape), and Barbeau's test will be performed.

All patients will receive guidance on post-procedure care, consisting of keeping the punctured limb at rest and refraining from physical exertion on the day of the procedure. Social, demographic, clinical, and procedure-related variables will be collected from all patients.

\section{Randomization}

The randomization.com website will be used to randomly allocate individuals into each group. All numbers in the randomization list will be placed in sealed brown envelopes, to be opened by a nurse at the end of the procedure, thus determining the allocation group.

\section{Clinical data}

Clinical and sociodemographic data will be recorded by a nurse during preparation for the procedure. The primary outcome is the incidence of radial artery occlusion, defined as a "D"-pattern curve on Barbeau's test after the intervention. Secondary outcomes are Barbeau's test curve change, additional time to achieve haemostasis (including need for additional compression); incidence of bleeding at the puncture site, according to Early Discharge after Transradial Stenting of Coronary Arteries (EASY) study definitions; severity of pain, evaluated on a visual analogue scale; development of clinically relevant arteriovenous fistula; development of radial pseudo aneurysm; and any complication at the access site that requires vascular surgery intervention ${ }^{(13-14)}$ and costs between the two devices.

\section{Statistical analysis}

Data will be presented as mean \pm standard deviation or median and interquartile ranges, as appropriate. Categorical variables will be analysed with the chi-square test, Student $t$-test, Pearson test, or Mann-Whitney $U$ test, as appropriate. The significance level will be set at 0.05 , and all analyses will be performed in the PASW Statistics 18.0 software environment (Chicago, IL, USA).

\section{RESULTS}

This manuscript does not present results because it is a study protocol.

\section{口DISCUSSION}

This single-centre randomized clinical trial aims to compare the incidence of radial artery occlusion between two haemostasis techniques - theTRBand ${ }^{\mathrm{TM}}$ device versus an elastic adhesive bandage - in individuals undergoing percutaneous cardiovascular interventions through the radial artery approach. The incidence of bleeding will also be evaluated.

The primary endpoint of this study is radial artery occlusion, and the secondary endpoint is the incidence of bleeding at the access site. It is important to highlight that both are safety endpoints. Notwithstanding, these two endpoints are, together, the most relevant vascular complications after interventions performed through the radial artery.

On one hand, haemostasis with an elastic adhesive bandage device is now widely used in clinical practice in Brazilian catheterization laboratories, and is a low-cost strategy. On the other hand, there is no robust evidence to support the safety of this approach.

The results of this RCT should provide valuable additional information regarding the best approach to haemostasis after percutaneous cardiovascular interventions performed through the radial route.

\section{口 REFERENCES}

1. Ferrante G, Rao SV, Jüni PT, Costa BR, Reimers B, Condorelli G, et al. Radial versus femoral access for coronary interventions across the entire spectrum of patients with coronary artery disease: a meta-analysis of randomized trials. JACC Cardiovasc Interv. 2016;9(14):1419-34. 
2. Jolly SS, Amlani S, Hamon M, Yusuf S, Mehta SR. Radial versus femoral access for coronary angiography or intervention and the impact on major bleeding and ischemic events: a systematic review and meta-analysis of randomized trials. Am Heart J. 2009;157(1):132-40.

3. Hamon M, Pristipino C, Di Mario C, Nolan J, Ludwig J, Tubaro M, et al. Consensus document on the radial approach in percutaneous cardiovascular interventions: position paper by the European Association of Percutaneous Cardiovascular Interventions and Working Groups on Acute Cardiac Care and Thrombosis of the European Society of Cardiology. Euro Intervention. 2013; $8(11): 1242-51$

4. Jolly SS, Yusuf S, Cairns J, Niemelä K, Xavier D, Widimsky P, et al. Radial versus femoral access for coronary angiography and intervention in patients with acute coronary syndromes (RIVAL): a randomised, parallel group, multicentre trial. Lancet. 2011;377(9775):1409-20.

5. Mitchell MD, Hong J A, Lee BY, Umscheid CA, Bastsch SM, Don CW. Systematic review and cost-benefit analysis of radial artery access for coronary angiography and intervention. Circ Cardiovasc Qual Outcomes. 2012:5(4):454-62.

6. Kotowycz MA and Dzavík V. Radial artery patency after transradial catheterization. Circ Cardiovasc Interv. 2012;5(1):127-33.

7. Benite, Vranckx P, Jaspers L, Jackmaert R, Poelmans C, Comninx R. Frequency of a positive modified Allen's test in 1,000 consecutive patients undergoing cardiac catheterization. Cathet Cardiovasc Diagn 1996;38(4):352-4.
8. Barbeau GR, Arsenault F, Dugas L, Simard S, Larivière MM. Evaluation of the ulnopalmar arterial arches with pulse oximetry and plethysmography: comparison with the Allen's test in 1010 patients. Am Heart J. 2004 Mar;147(3):489-93.

9. Cubero JM, Lombardo J, Pedrosa C, Diaz-Bejarano D, Sanchez B, Fernandez V. Radial Compression guided by mean Artery Pressure versus standard compression with a pneumatic device (RACOMAP). Cathet Cardiovasc Interv. 2009;73(4):467-72

10. Pancholy S. Impact of two different hemostatic devices on radial artery outcome after transradial catheterization. J Invasive Cardiol. 2009;21(3):101-4.

11. Rathore S, Stables RH, Pauriah M, Hakeem A, Mills JD, Palmer ND. A randomized comparison of TR band and Radistop hemostatic compression devices after transradial coronary intervention. Cathet Cardiovasc Interv. 2010;76(5):660-7.

12. Pancholy S, Coppola J, PatelT, Roke-Thomas M. Prevention of radial artery occlusion-patent hemostasis evaluation trial (PROPHET Study): a randomized comparison of traditional versus patency documented hemostasis after transradial catheterization. Cathet Cardiovasc Interv. 2008;72(3):335-40.

13. Bertrand OF, De Larochellière R, Rodés-Cabau J, Proulx G, Gleeton O, Nguyen CM, et al. A randomized study comparing same-day home discharge and abciximab bolus only to overnight hospitalization and abciximab bolus and infusion after transradial coronary stent implantation. Circulation. 2006;114(24):2636-43.

14. Pasero C, McCaffery M. Pain Assessment and Pharmacological Management. St Louis: Mosby-Elsevier; 2011.
Corresponding author:

Eneida Rejane Rabelo-Silva

E-mail: eneidarabelo@gmail.com
Received: 12.08.2017

Approved: 03.26.2018 